\title{
Gestão dos Serviços Públicos e Participação Cidadã: Estudo com os Beneficiários do Programa Bolsa Família
}

\section{Public Service Management and Citizen Participation: a Study with the Beneficiaries of the Family Allowance Program}

Vera Lúcia Peixoto Santos Mendes * Doutora em Administração pela EAUFBA. Professora da EAUFBA, Salvador/BA, Brasil.

Angela Maria Gordilho Barbosa Doutora em Urbanismo pela Universidade Paris XII, França. Professora da FIB, Salvador/BA, Brasil.

Jorgas Marques Rodrigues Mestre em Organização e Avaliação dos Sistemas de Cuidados à Saúde pela EEUFBA. Professor da FAMAM, Cruz das Almas/BA, Brasil.

* Endereço: Vera Lúcia Peixoto Santos Mendes

EAUFBA, Av. Reitor Miguel Calmon s/n, Vale do Canela, Salvador/BA, 40110-100. E-mail: vmendes@ufba.br

Copyright (C 2009 RAC. Todos os direitos, inclusive de tradução, são reservados. É permitido citar parte de artigos sem autorização prévia desde que seja identificada a fonte. 


\section{RESUMO}

Este trabalho objetiva analisar em que medida o Programa Bolsa Família [PBF] contribui para fortalecer a participação cidadã na gestão dos serviços públicos e identificar o grau de conhecimento dos beneficiários deste Programa sobre os seus direitos políticos. Para tanto, são realizadas revisões teóricas sobre a ampliação dos direitos e da participação cidadã à luz do Estado Democrático de Direito. Foi realizado um estudo multicasos, de natureza quantitativa, com 1.588 beneficiários do PBF em situação de uso de serviços básicos de saúde, em dez municípios baianos. Os resultados revelam que existe baixa predisposição à vida associativa e não se identificam os fóruns de participação, dificultando assim a discussão dos problemas de interesse coletivo, predominando o desconhecimento sobre os direitos políticos. Há baixa confiança nos poderes executivo e legislativo; os maiores percentuais de credibilidade encontram-se nas instituições religiosas $(74,1)$ e associações de moradores $(34,1)$, o que condiz com outros estudos realizados na América Latina. Com esta explanação conclui-se que o PBF não tem exercido uma função emancipatória, capaz de promover mudanças estruturantes, como ampliar a predisposição à vida associativa, a participação e o conhecimento sobre seus direitos políticos.

Palavras-chave: programa Bolsa Família; participação cidadã; serviços públicos; direitos políticos.

\section{ABSTRACT}

This paper aims to analyze to what extent the Family Allowance Program [FAP] contributes to strengthening citizens' participation in public services management and to identify the degree of knowledge of the Program Beneficiaries regarding their political rights. For this purpose, theoretical revisions were carried out, which focused on the expansion of the rights and citizens' participation in the light of the Democratic State under the Rule of Law. A multi-case study was carried out with 1,588 beneficiaries from the FAP who benefited from the basic health services in ten municipalities in the State of Bahia. The results show that there is low predisposition to associative life and the participation forums are not identified, hardening the discussion of the collective interest problems, with the predominance of the lack of knowledge concerning political rights. There is low confidence in the legislative and executive branches, and the higher credibility percentages are found at religious institutions $(74,1)$ and residents association, $(34,1)$, which matches other studies realized in Latin America. Accordingly, the conclusion is that the FAP has not performed an emancipating role that is capable of promoting structuring changes, such as expanding predisposition to associative life, participation and knowledge of their Political Rights.

Key words: family allowance program; citizen participation; public services; political rights. 


\section{INTRODUÇÃO}

No cenário das reformas estruturais do Estado brasileiro na década de 90 , os serviços públicos têmse reconfigurado e assumido novas funções e definições. Di Pietro (2006) considerou o termo Serviço Público como toda atividade material que a lei atribui ao Estado, para que a exerça diretamente ou por meio de seus delegados, para satisfazer necessidades coletivas, sob regime jurídico total ou parcialmente público. Assim, tem-se que o serviço público é uma incumbência do Estado, cuja criação se dá por Lei, sendo a sua gestão feita diretamente pelos órgãos que compõem a Administração Pública ou, indiretamente, por meio de concessão ou permissão, ou por pessoas jurídicas criadas pelo Estado para tal fim. Para a população usuária destes serviços parece não interessar tanto a forma de sua provisão como a universalização do acesso. Assim, este trabalho objetiva analisar em que medida o Programa Bolsa Família [PBF] contribui para fortalecer a participação cidadã na gestão dos serviços públicos de saúde, prestados diretamente pelo Estado e identificar o entendimento dos beneficiários deste Programa sobre os seus direitos políticos.

Na literatura internacional, são apontadas duas tendências sobre o que impulsiona essa participação. Uma supõe a criação de poderes equilibrados, de mecanismos que diminuam as vantagens dos atores sociais poderosos. A outra ressalta a importância de efetivação dos direitos civis e políticos, dado que não se pode criar o equilíbrio necessário sem direitos iguais à livre expressão, acesso à justiça, informação etc., além do fato de que os pobres devem ter um mínimo de seguridade econômica (Kliksberg, 2007). É nesta perspectiva de efetividade da participação que este trabalho se insere.

Neste trabalho, a participação cidadã é discutida tomando-se como referência o alicerce legal conquistado, a partir da Constituição brasileira de 1988 (Constituição da República Federativa do Brasil, 1988), e analisando-se uma política social de erradicação da extrema pobreza e da marginalização, denominado Programa Bolsa Família [PBF]. Para tanto, inicialmente apresenta-se o que se entende por Direitos Políticos, os desafios na implantação do PBF e, por fim, são apresentados os aspectos metodológicos e discutidos os resultados do estudo empírico realizado em dez municípios baianos com os beneficiários do PBF.

\section{A ERA DOS DiREITOS}

No século XX, uma das principais contribuições sobre a constituição dos direitos, no campo teórico, veio de Marshall (1950). De acordo com este autor, os direitos civis, conquistados no século XVII, em resposta ao absolutismo, significariam liberdade individual de falar, pensar e acreditar, o direito à propriedade, o direito de ir e vir, o direito à realização de contratos, à vida e à segurança. Os direitos políticos foram alcançados no século XIX e incluíam o direito de participar do poder político como membro de uma sociedade, investido de autoridade política ou como eleitor. Os direitos sociais, uma conquista dos países de capitalismo avançado, no século XX seria a extensão do bem-estar econômico e social necessários para se viver uma vida civilizada, obedecendo a padrões que são relativos a uma dada sociedade (Ministério da Saúde. Secretaria de Assistência à Saúde, 2002).

No Estado Democrático de Direito [EDD], o regime político permite aos governados (povo) a efetiva participação no processo de formação da vontade pública (governo). O EDD fundamenta-se: na soberania, que significa o poder máximo que tem um Estado para fazer valer suas decisões e autoridade no seu território; na cidadania, a partir da qual se cria a qualidade do cidadão, caracterizada pelo livre exercício dos direitos e deveres políticos, civis e sociais; nos valores do trabalho e da livre iniciativa e no pluralismo político (Constituição da República Federativa do Brasil, 1888). Embora sejam plurais os fundamentos do EDD, neste trabalho, são enfatizados os aspectos relativos aos Direitos Políticos, fazendo-se uma leitura sob o ponto de vista da cidadania e das questões referentes à 
soberania popular que, pela Constituição Federal de 1988, deve ser exercida pelo sufrágio universal e pelo voto.

De acordo com Moraes (2005), são os Direitos Políticos que investem o indivíduo do status activae civitatis, permitindo-lhe o exercício concreto da liberdade de participação nos negócios políticos do Estado, conferindo-lhe os atributos da cidadania. Pelo direito de cidadania, o indivíduo participa da vida pública do País, votando e sendo votado, e exercita seus direitos políticos, seu poder de intervenção direta, ou só indireta, mais ou menos ampla, conforme a intensidade de gozo desses direitos. Os direitos políticos consistem no poder que o cidadão tem para interferir na estrutura governamental, do qual advém a cidadania como atributo político do direito de participar do governo e de ser ouvido mediante representação política. No direito pátrio, ser cidadão significa que o indivíduo é titular dos direitos políticos de votar e de ser votado, sendo o voto a expressão da vontade em processo decisório e ato político que materializa, na prática, o direito público subjetivo de sufrágio.

Existem várias definições de Direitos Políticos; uma delas consta em Ferreira (2002, p. 166) que, ao citar Bueno, afirma serem estes "as prerrogativas, os atributos, a faculdade ou o poder de intervenção dos cidadãos ativos no governo de seu país" (Ferreira, 2002, p. 116). Destarte, os Direitos Políticos asseguram a participação do indivíduo no governo do seu país, votando ou sendo votado. Convém salientar que votar ou ser votado está positivado na norma constitucional; contudo concordamos com a definição apresentada por Magalhães (como citado em Dorella, 2006, p. 21):

São direitos de participação popular no poder do Estado, que resguardam a vontade manifestada individualmente por cada eleitor sendo que a sua diferença essencial para os Direitos individuais é que, para estes últimos, não se exige nenhum tipo de qualificação em razão da idade e nacionalidade para o seu exercício, enquanto que para os Direitos Políticos, determina a constituição os requisitos que o indivíduo deve preencher.

Votar e ser votado, portanto exercer os Direitos Políticos, no atual sistema eleitoral brasileiro implica saber escolher um representante, o que depende de outros direitos, como o direito social à educação, não apenas para saber ler e escrever, ser alfabetizado, mas como forma de conscientização política da população. Depende, ainda, de direitos econômicos, expressos por uma política econômica que busque a democracia econômica, sem a qual a democracia política fica sempre incompleta, ameaçada e sujeita ao clientelismo.

Bobbio (2004) ressaltou que a multiplicação cada vez mais acelerada dos direitos do homem deixa explícita a necessidade de fazer referência ao contexto social no qual estes direitos proliferam. $\mathrm{O}$ autor ressalta que jamais poderia ser aprovado, por resolução da Organização das Nações Unidas, um Plano de Ação para os idosos, em 1982, se não tivesse aumentado a longevidade.

Há uma universalidade no eventual gozo dos direitos de liberdade, que não vale para os direitos sociais e políticos, diante dos quais os indivíduos só são iguais genericamente, mas não especificamente, existindo, com referência a estes direitos, diferenças de grupos de indivíduos para outros grupos de indivíduos. Um dos exemplos é o fato de que, durante séculos, só os homens votavam e, ainda hoje, os menores de 16 anos não têm este direito. Isto significa que, na afirmação e no reconhecimento dos direitos políticos, são consideradas as diferenças que justificam um tratamento desigual. Igualdade e diferença têm relevância diversa, se estão em jogo direitos de liberdade, direitos políticos e sociais. Esta é uma das razões que fez proliferar estes direitos, sendo que a sua proteção requer a intervenção ativa do Estado (Bobbio, 2004). O autor adverte, contudo, que as declarações e cartas de direitos são expressões de boas intenções ou expectativas, sem garantia de realização, além da boa vontade do Estado. Para que estes direitos ou expectativas tenham efetivação, é preciso acolhimento pela legislação civil, capacidade ou poder de influir na formação da vontade do Estado e, principalmente, exercitar a participação cidadã, o que quer dizer: participar na escolha dos representantes políticos e na gestão dos serviços públicos em um momento em que o Estado assume papel indutor-normativo ou regulador, restando à sociedade civil a busca de novas alternativas de enfrentamento da exclusão social crescente, pressionando para que este Estado efetivo tenha como sua primeira obrigação a garantia dos direitos fundamentais do cidadão. 
No Brasil, mesmo sem a garantia dos direitos de primeira geração, surgiram os direitos de quarta geração, tais como o direito ao ambiente ecologicamente equilibrado, ao desenvolvimento e às informações corretas, sem a contaminação das mídias eletrônica e impressa (Ferreira, 2002). Os direitos de quarta geração significam, sobretudo, o direito à democracia, não só política, mas também econômica e ao pluralismo. Deles depende a concretização da sociedade aberta do futuro, em sua dimensão de máxima universalidade, para a qual parece o mundo inclinar-se no plano de todas as relações de convivência.

Não é possível falar em democracia econômica, quando o Brasil ainda possui mais de 16 milhões de analfabetos, concentrando-se $50 \%$ destes no Nordeste. O País apresenta uma das piores concentrações de renda do mundo, só sendo superado por poucos países, tais como Serra Leoa, República CentroAfricana e Suazilândia. Conforme dados apontados por Pinto, Brant, Sampaio e Pascom (2000, p. 521) "a renda dos $20 \%$ mais ricos é trinta e duas vezes maior que aquela dos $20 \%$ mais pobres".

Embora positivados constitucionalmente como direitos de primeira geração, é neste cenário dos direitos de quarta geração, em um contexto de pobreza e exclusão social, que se insere o direito político ao Programa Bolsa Família. Em síntese, a evolução dos direitos humanos dá-se pari passu com o desenvolvimento social, técnico e cultural de cada sociedade.

\section{A PARTICIPAÇÃo Cidadã Na ERA dos Direitos}

No Brasil, o tema da participação cidadã não é inédito; porém, quando se analisam alguns indicadores de participação, observa-se que, apesar de ter adquirido um novo status na agenda sociopolítica, em decorrência das reformas estruturais da década de 90 e das experiências locais, a exemplo do orçamento participativo em Porto Alegre, os avanços ainda são incipientes e continuam as dificuldades do acesso da população em situação de pobreza, aos serviços públicos. Contudo o êxito da prestação destes serviços depende do apoio dos principais interessados: os cidadãos, para os quais a alternativa de exit, ou saída, traz como consequiência a piora na qualidade do serviço público. Estes serviços têm como objetivos: democratizar as relações entre estado e sociedade civil; promover a accountability; adotar estratégias que estimulem os mecanismos de participação dos usuários na sua gestão; introduzir melhorias contínuas no processo de produção, de modo a elevar a eficiência para reduzir desperdícios e gastos, mantendo-se os níveis de qualidade e tendo como principal agente o cidadão.

A reação à decepção é entendida pela Teoria da Escolha Pública como afastamento ou exit, no sentido de abandonar o consumo de um produto ou serviço. Hirschman (1982) refere-se à existência de outra saída (voice), como a de se manifestar, engajando-se em ações que vão da reclamação individual até a ação popular de interesse geral. Na maioria dos casos, a manifestação é uma ação pública por natureza e pode enfraquecer a reação do tipo afastamento, aumentando a tendência à mudança das ações na esfera pública. Portanto, a possibilidade de manifestar-se está associada ao auto-reconhecimento enquanto cidadão, e a saída, ir embora, associa-se ao comportamento do consumidor, tão enfatizado pelo Estado gerencial.

Kliksberg (2007) faz uma revisão de experiências que são referências internacionais sobre a América Latina, na qual analisa a gestão participativa de Porto Alegre no Brasil, a de um município autogestor em Villa El Salvador, no Peru, e o modelo de cidade includente, sustentado e participativo de Rosário, na Argentina. Nesta revisão, o autor ressalta que, apesar das especificidades e diferenças históricas, existem aspectos comuns relevantes, tais como: a participação se constitui em uma estratégia mestra para reduzir as desigualdades; para mobilizar a participação é necessário um projeto político, econômico e social democratizante, coerente e centrado na inclusão social, na eqüidade e no desenvolvimento pleno da cidadania; é necessário que as experiências de participação democratizante se transformem em projetos coletivos; a existência de capital social e cultural, nos quais se incluem recursos financeiros, infra-estrutura, capital fixo, recursos naturais e bens de capital. Além disso, é 
decisivo o modelo organizacional, a gerência social e um processo democrático que facilite a aprendizagem, o empoderamento dos setores excluídos, aumentando assim o capital social nas dimensões referentes à confiança, capacidade de associativismo e consciência cívica e dos valores éticos positivos.

\section{Gestão do Programa Bolsa família}

É a Administração Pública, em sua dimensão intergovernamental, que executa o Programa Bolsa Família [PBF]. Trata-se de um programa de gestão descentralizada, em conjunto com os entes federados, estabelecido no Art. $8^{\circ}$, da Lei $\mathrm{n}^{\mathrm{o}}$ 10.836, de 2004 e regulamentado pelo Decreto $\mathrm{n}^{\mathrm{o}} 5.209$, de 17/09/2004. O PBF tem como objetivos: o alívio imediato da pobreza, por meio da transferência direta de renda às famílias beneficiárias; a ruptura do ciclo da pobreza, por meio das condicionalidades, que reforçam direitos sociais nas áreas de saúde e educação; e o desenvolvimento das famílias, por meio dos Programas Complementares, que são ações coordenadas dos governos e da sociedade nas áreas de geração de trabalho e renda, alfabetização, microcrédito, desenvolvimento social, entre outras, com foco nas famílias beneficiárias ${ }^{(1)}$. Segundo informações do Banco Mundial, o Programa atendia, em 2005, mais de 8,7 milhões de famílias e, ao mesmo tempo, ampliava a sua cobertura, buscando aperfeiçoar seu desenho de gestão e de implementação. Apesar de os benefícios do Programa serem repassados diretamente às famílias, o Bolsa Família se fundamenta na participação de todos os entes federados. Cada esfera de governo tem atribuições e competências diferenciadas em relação ao PBF. Especificamente em relação à gestão de benefícios, existe a portaria de gestão de benefícios (Portaria $\left.n^{\circ} 555,2005\right)$ que define as atribuições de cada um dos entes, presentes nos artigos 20 a 23, sendo responsabilidade da União, através do Ministério do Desenvolvimento Social e Combate à Fome, a gestão do PBF em âmbito federal. A inclusão das famílias no Programa é operacionalizada pela Secretaria Nacional de Renda da Cidadania [SENARC], que realiza a concessão do benefício, segundo regras predeterminadas.

São atribuições da Secretaria Nacional de Renda da Cidadania [SENARC]: elaborar as normas e regulamentos que formam o desenho normativo do PBF; gerir o Cadastro Único dos Programas Sociais; fiscalizar a gestão local do PBF; promover melhorias e fomentar a utilização do Sistema de Gestão de Benefícios por parte dos gestores municipais, coordenadores estaduais, membros das instâncias de controle social e integrantes da Rede Pública de Fiscalização do PBF, com vistas à eficiência, à eficácia e à transparência das ações de gestão de benefícios; promover o intercâmbio das boas práticas entre os gestores municipais do PBF e a divulgação destas em nível nacional; realizar atividades de gestão de benefícios; promover ações de capacitação dos agentes responsáveis pelas atividades de gestão de benefícios e dos membros das instâncias de controle social, em parceria com os demais entes federativos. Ainda na esfera federal, os Ministérios da Saúde e da Educação também desempenham importante papel na gestão de benefícios, uma vez que o acompanhamento do cumprimento das condicionalidades tem efeitos diretos sobre os benefícios das famílias, conforme Portaria $\mathrm{n}^{\mathrm{o}} 551$ (2005).

Nos Estados, a participação na gestão de benefícios está focada no papel coordenador dos municípios que formam seu território. Exercem a função de promotores do desenvolvimento das atribuições municipais, estimulando uma ação local qualificada e fornecendo o suporte e o apoio técnico necessários ao planejamento e desenvolvimento do Programa. São competências dos coordenadores estaduais: promover o credenciamento ao Sistema de Gestão de Benefícios [SIBEC] dos funcionários do Governo Estadual e dos membros da instância de controle social; divulgar, aos demais órgãos públicos estaduais e à sociedade civil organizada, informações relativas aos benefícios do PBF e dos Programas Remanescentes, propiciando, assim, maior transparência às atividades de gestão de benefícios realizadas pelos municípios dentro do seu Estado; realizar ações de capacitação dos agentes municipais e estaduais responsáveis pela gestão de benefícios em parceria com o MDS; acompanhar a gestão de benefícios desenvolvida pelos municípios em seu Estado, prioritariamente via 
SIBEC, e ainda informar à SENARC eventuais irregularidades e/ou denúncias identificadas na prestação dos serviços de competência do Agente Operador ou de sua rede credenciada na localidade: correspondente bancário, agentes lotéricos etc.

No modelo de gestão descentralizada do PBF, gestores municipais são os principais agentes públicos do Programa junto às famílias. Como executores locais do PBF, os gestores municipais podem identificar mudanças socioeconômicas das famílias e realizar as devidas atividades de gestão de benefícios, de forma centralizada ou descentralizada. O gestor municipal deve acompanhar a mobilidade geográfica, característica presente neste estrato da população, promovendo os ajustes necessários nos cadastros das famílias beneficiárias.

São competências dos gestores municipais: verificar periodicamente a conformidade da situação das famílias beneficiárias do PBF e dos Programas Remanescentes aos critérios de elegibilidade destes programas, se necessário, utilizando técnicas de amostragem estatística, de modo a adequar os benefícios financeiros à realidade das famílias; realizar o credenciamento dos funcionários da prefeitura e dos integrantes da instância de controle social municipal no SIBEC, bem como capacitar os usuários; atender aos pleitos de informações e de esclarecimentos da Rede Pública de Fiscalização; divulgar as informações relativas aos benefícios do PBF e dos Programas Remanescentes aos demais órgãos públicos locais e à sociedade civil organizada; manter a SENARC informada sobre os casos de deficiências ou irregularidades identificadas na prestação dos serviços de competência do Agente Operador ou de sua rede credenciada na localidade: correspondente bancário, agentes lotéricos etc.

Assim como os demais programas de garantia de renda mínima à população pobre, o PBF se caracteriza como estratégia de ruptura do ciclo intergeracional da pobreza, dado que as famílias passam a ter um complemento de renda para os filhos freqüentarem a escola e melhorarem as condições de saúde. Para evitar a duplicidade de ações entre as esferas federal e municipal, a União utilizou três estratégias: a possibilidade de integrar programas municipais de renda com o PBF, a adesão formal dos municípios ao PBF, ocorrida em 2005, condicionada à indicação de um gestor municipal do programa, à indicação de instância de controle social e ao estabelecimento de sistemáticas de apoio financeiro para a gestão estadual e local (Mesquita, 2006).

De acordo com Mesquita (2006), o PBF inova ao estabelecer relações de parcerias entre os entes federativos, mostrando-se como importante instrumento de mobilização popular, configurando-se como ação estruturadora do sistema de proteção social brasileiro e, ao focar sobre a família, articula outras políticas sociais para os beneficiários do Programa.

\section{ASPECTOS METODOLÓGICOS}

Foi realizado estudo multicasos descritivo, exploratório, de abordagem quantitativa (Yin, 2005), utilizando-se o banco de dados coletados a partir do Projeto "Tecnologias de Gestão no Combate à Pobreza e às Desigualdades Sociais: desafios da Sociedade e dos Serviços Públicos na Bahia" (Mendes et al., 2006). Foram aplicados questionários previamente testados, com uma amostra de 1.588 beneficiários do $\mathrm{PBF}$, o que representa $20 \%$ destes em cada município; com mais de três anos de recebimento do benefício, o que dá mais confiabilidade às respostas, tendo em conta a rotatividade dos beneficiários, e em situação de uso de serviços básicos de saúde. A coleta de dados foi efetuada na semana de 10 a 16 de julho de 2006, sendo realizada por bolsistas de iniciação científica, devidamente treinados e supervisionados. O locus da pesquisa corresponde a 10 municípios baianos ${ }^{(2)}$, sendo selecionada para coleta a Unidade Básica de Saúde do bairro onde existia maior número de beneficiários do PBF cadastrados.

Para a análise, foram utilizadas medidas de freqüências simples, empregando-se o pacote de análise estatística SPHINX. Para analisar em que medida o Programa Bolsa Família [PBF] contribui para fortalecer a participação cidadã na gestão dos serviços públicos, foram utilizados os seguintes 
indicadores e suas correspondentes variáveis: I - Características da amostra; II - Capital social ${ }^{(3)}$, avaliado pelo número e percentual de respostas sobre as instituições em que mais confiam; III - Vida associativa avaliada pela seguinte variável: a) participação em associações, sindicatos ou conselhos; IV - Conhecimento das instâncias de participação avaliado por: a) conhecimento da existência de Conselho Municipal de Saúde; b) participação no Conselho de Saúde; c) fórum de discussão dos problemas de saúde; V - Avaliação dos principais problemas do município/bairro; a) discussão no bairro sobre problemas relativos a água, esgoto, lixo, saúde e educação profissional; b) discussão dos problemas de saúde pela comunidade. Para identificar o grau de conhecimento dos beneficiários do PBF sobre os seus Direitos Políticos, foi utilizado o indicador Entendimento sobre os Direitos Políticos.

\section{APRESENTAÇÃO, ANÁLISE E DISCUSSÃO dOS RESULTADOS}

Inicialmente, caracteriza-se a amostra, salientando-se que a da cultura política dos municípios, embora não seja objeto deste estudo, não pode ser considerada homogênea. Posteriormente, são discutidos os resultados à luz da literatura examinada e dos indicadores estabelecidos.

\section{Características da Amostra}

De acordo com a Figura 1, observa-se maior concentração de usuários entrevistados em Salvador $(44,1 \%)$ e Valença $(11,5 \%)$.

Figura 1: Gráfico da Distribuição da Amostra por Município - BA, 2007

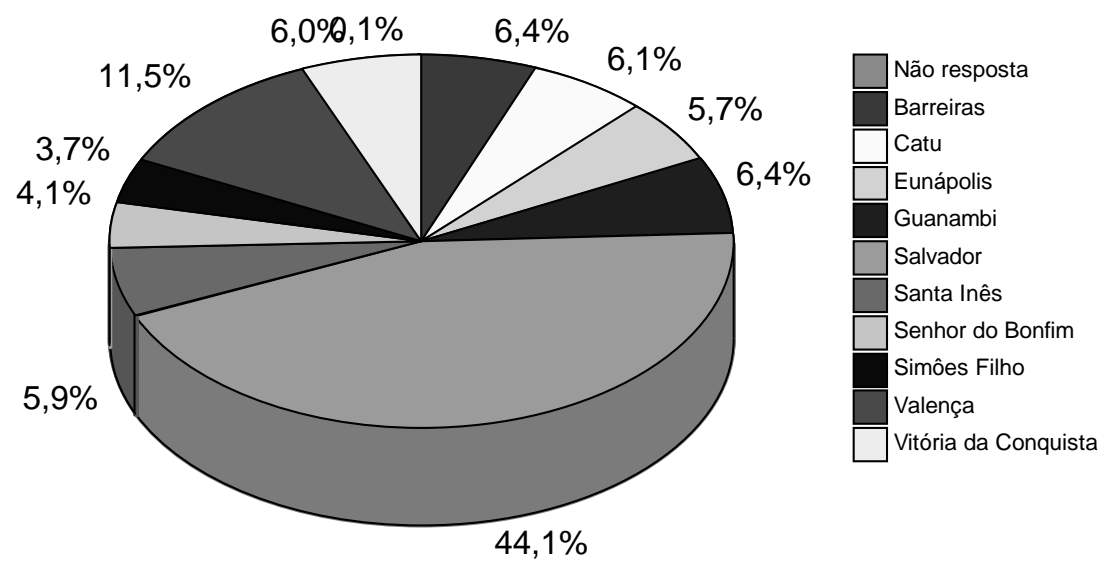

Fonte: pesquisa de campo.

No que se refere à distribuição da amostra por gênero, encontra-se maior percentual de mulheres $(78,9)$; quanto à faixa etária, predominam a de 18 a 30 anos (39\%) e a de 31 a 45 anos (38,2\%); no que diz respeito à escolaridade, apresenta maior percentual o primeiro grau incompleto $(39,2)$ e, quanto à ocupação, encontra-se maior freqüência de donas de casa $(40,4 \%)$. Isto significa que se trata de amostra constituída principalmente por mulheres em idade reprodutiva, com baixo grau de instrução e sem remuneração pela ocupação que desempenham. 


\section{Capital Social}

A análise das respostas sobre as instituições em que mais confiam, revela que a instituição religiosa é a que apresenta maior percentual $(74,1)$, seguida de associações de moradores $(34,1)$ e serviços de saúde $(30,7)$. Este resultado encontra ressonância no estudo realizado pelo Banco Mundial com 60.000 pobres de 60 países citado por Narayan e outros (como citado em Kliksberg, 2007), que afirmam ser a Igreja a segunda instituição mais acreditada, porque trabalha junto com eles, sem tratá-los como categoria inferior. Na primeira e segunda posição estão aquelas instituições da própria comunidade, pois recuperam a auto-estima individual e coletiva (Tabela 1).

Tabela 1: Respostas sobre as Três Instituições que Mais Confiam - BA, 2007

\begin{tabular}{lll}
\hline Instituições que mais confiam & $\mathbf{N}^{\mathbf{0}}$ & Freq. \\
\hline Instituição Religiosa (igreja) & 1177 & $74,1 \%$ \\
\hline Associações de moradores & 541 & $34,1 \%$ \\
\hline Serviços de saúde & 487 & $30,7 \%$ \\
\hline Prefeitura & 366 & $23,0 \%$ \\
\hline Embasa/ Serviço Municipal de água & 339 & $21,3 \%$ \\
\hline CEFET/Agrotécnica & 305 & $19,2 \%$ \\
\hline Câmara de Vereadores & 184 & $11,6 \%$ \\
\hline Nenhum & 100 & $6,3 \%$ \\
\hline Não resposta & 4 & $0,3 \%$ \\
\hline TOTAL & 1588 & \\
\hline Fonte: pesquisa de campo. & &
\end{tabular}

Por outro lado, ainda conforme a Tabela1, a Câmara de Vereadores apresenta os menores percentuais de confiança $(11,6)$, seguida da Escola Agrotécnica do CEFET $(19,2)$ e do Serviço Municipal de Água $(21,3)$. Tais resultados revelam o descrédito da população em situação de pobreza em relação ao poder legislativo municipal e em relação ao serviço público de educação profissionalizante. Isto pode estar relacionado às características da amostra, já que a maioria dos entrevistados tem o primeiro grau incompleto, embora já possuam idade para estar cursando o ensino médio. Assim, este equipamento público não é acessível a esta camada da população. Os baixos percentuais de credibilidade no Serviço Municipal de Água podem estar relacionados à pouca freqüência com que este é disponibilizado à população em situação de pobreza. Isto significa que o Estado brasileiro obriga o cidadão a votar, mas nega-lhe o direito aos serviços necessários a uma vida digna, como água e educação profissionalizante.

\section{Vida Associativa}

A participação pode funcionar como promessa de reequilíbrio social e de desenvolvimento. Assim, apresenta-se o indicador que avalia a participação dos beneficiários do PBF em associações, nos municípios pesquisados, observando-se que há baixa predisposição dos beneficiários do PBF à vida associativa (Tabela 2).

Tabela 2: Respostas sobre Participação em Alguma Associação de Bairro / Sindicato/ Conselho BA, 2007

\begin{tabular}{lll}
\hline Participação em Associação de bairro, sindicato ou conselho & No. & Freq. \\
Sim & 241 & $15,2 \%$ \\
Não & 1347 & $84,8 \%$ \\
TOTAL & 1588 & $100 \%$ \\
\hline
\end{tabular}

Fonte: pesquisa de campo. 


\section{Conhecimento das Instâncias de Participação}

Quando perguntados sobre a existência do Conselho Municipal de Saúde, 79,8\% responderam que o desconhecem (Tabela 3). A participação tem função pedagógica, para a mudança da cultura política. Envolve socialização e pode promover o desenvolvimento das capacidades sociais e políticas dos indivíduos. Assim, o conhecimento das instâncias formais de participação é fundamental para a democracia participativa e conseqüentemente para a cidadania ativa.

Tabela 3: Respostas sobre a Existência do Conselho Municipal/Local de Saúde - BA, 2007

\begin{tabular}{|lll|}
\hline $\begin{array}{l}\text { Conhecimento da Existência de Conselho de Saúde } \\
\text { Municipal/ Local de Saúde }\end{array}$ & No. & Freq. \\
\hline Não resposta & 2 & $0,1 \%$ \\
Sim & 319 & $20,1 \%$ \\
Não & 1267 & $79,8 \%$ \\
\hline TOTAL & 1588 & $100 \%$ \\
\hline Fonte: pesquisa de campo & & \\
\hline
\end{tabular}

Deve-se ressaltar ainda que apenas $1,9 \%$ já participou do Conselho de Saúde (Tabela 4). Este aspecto demonstra que, teoricamente, a existência destes espaços de participação é fundamental para democratizar e ampliar o espaço público. Contudo, conforme afirma Mesquita (2006), há dúvidas sobre a efetividade desta iniciativa, devido à possivel cooptação dos participantes pelo poder público e também pelo desconhecimento ou falta de informação sobre como funciona a instância de participação e seus critérios (Carvalho, 1995).

Tabela 4: Respostas sobre se já Participou ou Alguém da Família, no Conselho Municipal/Local de Saúde - BA, 2007

\begin{tabular}{lll}
\hline Participação no Conselho Municipal/local de Saúde & No. & Freq. \\
Sim & 30 & $1,9 \%$ \\
Não & 289 & $18,2 \%$ \\
Não resposta & 1269 & $79,9 \%$ \\
TOTAL & 1588 & $100 \%$ \\
\hline
\end{tabular}

Fonte: pesquisa de campo.

Quando analisadas as respostas positivas sobre o fórum de discussão dos problemas de saúde, revela-se que estes são predominantemente discutidos pelos Agentes Comunitários de Saúde [ACS] (Tabela 5). Na verdade, esta não seria a instância de discussão dos problemas de saúde da coletividade; contudo isso ocorre provavelmente pelo fato de estes profissionais habitarem na comunidade, adquirem a sua confiança, embora não tenham legitimidade para dar encaminhamento aos problemas intersetorias apresentados, a exemplo da falta de pavimentação das ruas, saneamento e violência, que podem causar problemas de saúde. Isto revela, ainda, que as instâncias colegiadas legalmente constituídas para discutir e enfrentar os problemas de saúde não estão incluindo este segmento da população. O trabalho dos Agentes Comunitários de Saúde tem sido relevante para reduzir a mortalidade infantil e melhorar os indicadores de saúde, mas não se constitui em um fórum de discussão coletiva, dada a característica do trabalho destes profissionais, que se faz através de visitas domiciliares. 
Tabela 5: Respostas Afirmativas sobre com quem são Discutidos os Problemas de Saúde - BA, 2007

\begin{tabular}{|lll}
\hline Fórum de Discussão dos Problemas de Saúde & $\mathbf{N}^{\mathbf{0}}$ & Freq. \\
\hline Não resposta & 942 & $59,3 \%$ \\
ACS & 357 & $22,5 \%$ \\
Outros & 104 & $6,5 \%$ \\
Associações & 79 & $5,0 \%$ \\
Inst. Religiosas & 68 & $4,3 \%$ \\
Secretaria Municipal de Saúde & 31 & $2,0 \%$ \\
Conselho Municipal de Saúde & 7 & $0,4 \%$ \\
\hline TOTAL & 1588 & $100 \%$ \\
\hline Fonte: pesquisa de campo. & & \\
\hline
\end{tabular}

\section{Avaliação quanto aos Principais Problemas do Município/Bairro}

Quando perguntados sobre os principais problemas do município/bairro, predominam as respostas referentes à falta de calçamento e ruas esburacadas $(22,7 \%)$, violência $(17,8 \%)$ e falta de saneamento básico (16,9\%). Poucos reconhecem como problema o sistema educacional precário (2,5\%), a pobreza e a fome (2,7\%), o desemprego (7,8\%) (Tabela 6). Por se tratar de população em situação de pobreza, seria esperado que o desemprego, a pobreza e a fome fossem considerados os principais problemas. Contrariamente a estes achados, o LatinBarómetro (2005 como citado em Kliksberg, 2007, p. 77) afirma que "un $75 \%$ de los trabajadores de la región están preocupados de quedar sin trabajo en los próximos 12 meses". E afirma ainda: "la inquietud es muy fundada. En un 59\% de los hogares una persona ha estado desempleada en los últimos 12 meses".

Tabela 6: Respostas sobre o Principal Problema do Município/Bairro - BA, 2007

\begin{tabular}{lll}
\hline \multicolumn{1}{c}{ Principal problema do Município/Bairro } & No. & Freq. \\
Falta de calçamento ou buraco na rua & 361 & $22,7 \%$ \\
Pouca segurança ou violência & 283 & $17,8 \%$ \\
Falta de saneamento básico & 269 & $16,9 \%$ \\
Pouca assistência na saúde & 171 & $10,8 \%$ \\
Outros & 157 & $9,9 \%$ \\
Desemprego & 125 & $7,9 \%$ \\
Não tem problema & 110 & $6,9 \%$ \\
Muita pobreza ou fome & 43 & $2,7 \%$ \\
Sistema educacional precário & 39 & $2,5 \%$ \\
Iluminação precária & 24 & $1,5 \%$ \\
Não resposta & 6 & $0,4 \%$ \\
TOTAL & 1588 & $100 \%$ \\
\hline
\end{tabular}

Fonte: pesquisa de campo.

No que diz respeito à discussão de problemas relativos a água, esgoto, lixo, saúde e educação profissional, observa-se que, apesar da baixa credibilidade nos serviços de educação profissional e água, estes assuntos são pouco discutidos no bairro $(31,2 \%)$ (Figura 2$)$. 
Figura 2: Gráfico do Percentual de Respostas sobre se Discutem no Bairro Problemas relativos à Água, ao Esgoto, Lixo, à Saúde e Educação Profissional - BA, 2007

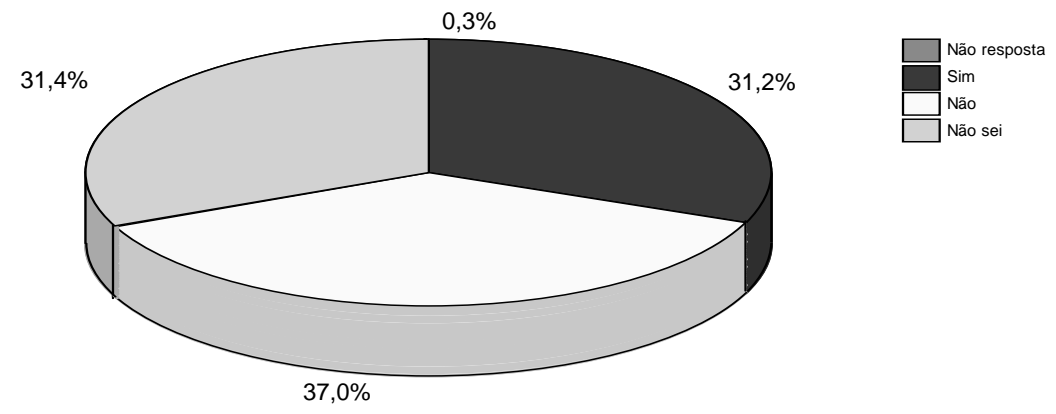

Fonte: pesquisa de campo.

De igual maneira, existe pouca discussão sobre os problemas de interesse coletivo e a análise da Tabela 7 demonstra que predominam as respostas negativas (59\%) quanto à discussão especificamente sobre os problemas de saúde na comunidade. Em síntese, embora a população usuária do PBF diagnostique a existência de problemas de interesse coletivo e não obstante existam instâncias colegiadas de participação para encaminhamento dos problemas, observa-se a falta de participação na gestão dos serviços públicos, mesmo para apresentar as demandas.

Tabela 7: Respostas sobre se os Problemas de Saúde são Discutidos na Comunidade - BA, 2007

\begin{tabular}{lll}
\hline \multicolumn{1}{c}{ Discutem problemas de saúde na comunidade } & $\mathbf{N}^{\mathbf{0}}$ & Freq. \\
Sim & 641 & $40,4 \%$ \\
Não & 947 & $59,6 \%$ \\
TOTAL & 1588 & $100 \%$ \\
\hline
\end{tabular}

Fonte: pesquisa de campo.

\section{Grau de ConheCimento sobre os DiReitos Políticos}

A análise da Tabela 8 revela que predominam as respostas «não sabe/não reponde» $(44,1 \%)$, sobre quais os direitos políticos, seguidas da resposta «votar» (23,5\%). Nota-se que não há citação de ser votado. Isto pode ser entendido como a renúncia de um direito fundamental.

Tabela 8: Respostas sobre Quais são os Direitos Políticos - BA, 2007

\begin{tabular}{lll}
\hline \multicolumn{1}{c}{ Resposta sobre direitos políticos } & $\mathbf{N}^{\mathbf{0}}$ de resp $^{(\mathbf{4})}$ & \multicolumn{1}{c}{ Freq. } \\
Não sabe ou não respondeu & 700 & $44,1 \%$ \\
Votar & 373 & $23,5 \%$ \\
Reivindicar ou cumprir com as promessas & 217 & $13,7 \%$ \\
Não tem direitos políticos & 158 & $9,9 \%$ \\
Garantir seus direitos básicos & 140 & $8,8 \%$ \\
Outros & 122 & $7,7 \%$ \\
Não resposta & 3 & $0,2 \%$ \\
TOTAL & 1588 & \\
\hline Fonte: pesquisa de campo. &
\end{tabular}

No que concerne ao indicador grau de conhecimento dos beneficiários do PBF sobre os seus Direitos Políticos, os resultados indicam a existência de baixo grau de entendimento dos beneficiários 

Família

do PBF quanto aos seus Direitos Políticos, o que pode fazer com que não os relacione com o PBF, compreendendo o Programa como uma benesse do Estado, reforçando assim a perspectiva da ideologia liberal na qual predomina o entendimento da cidadania passiva ou outorgada pelo Estado.

\section{CONCLUSÃO}

A efetiva descentralização de políticas sociais ocorre nos estados em que a ação política deliberada opera de modo eficiente (Arretche, 2002). Assim, o PBF, ao demandar ações coordenadas entre as diferentes esferas de governo, pode contribuir para fortalecer a capacidade de gestão local. Contudo isto não significa que se estabeleça uma relação democrática entre governantes e cidadãos de forma a possibilitar a participação cidadã e fortalecer o capital social. Democratizar as relações entre os poderes públicos e os cidadãos, significa promover a accountability, aumentar os mecanismos de participação dos usuários nas instâncias colegiadas.

Putnam (1996) retrata como a história mostra que tanto os estados quanto os mercados funcionam melhor em contextos cívicos e que o lugar a que se pode chegar depende do lugar de onde se veio. Assim, o amadurecimento cívico e político são fundamentais para o desenvolvimento humano. Isto se constrói, porém, a partir de instituições fortes.

Os resultados do estudo empírico demonstram que as instituições religiosas são as mais acreditadas pela população, seguidas das associações comunitárias; que há baixa predisposição a participar da vida associativa; que existe desconhecimento quanto ao fórum de participação e de discussão dos principais problemas de interesse coletivo, além do predomínio das respostas não sabe ou não responde sobre quais são os direitos políticos.

O Estado Democrático de Direito ampliou a pauta de direitos dos cidadãos e trouxe, como prerrogativa, a democracia. Na perspectiva do ideal republicano, considera-se o cidadão como portador de virtudes que o orientam para o mundo público, entendendo a cidadania como um conjunto de direitos e deveres ante os outros, o Estado e a sociedade, cujos valores são voltados para a ampliação do espaço público e para a vida associativa. Deste modo, é o cidadão, portador de direitos e deveres, o agente principal nesta relação entre governo e sociedade civil. Isto não se verificou no estudo empírico realizado com uma população em situação de pobreza e que apresenta desconhecimento sobre as instâncias de participação cidadã e de controle social, a exemplo do Conselho Municipal de Saúde, o que reduz a possibilidade de interferir no destino da aplicação dos recursos públicos, em prol da melhoria da infra-estrutura do espaço territorial onde vivem. Paralelamente, a população entrevistada, que se encontra em situação de pobreza, apresenta elevado percentual de analfabetos e está em fase reprodutiva. O fato de ser analfabeto já lhe retira a possibilidade de inserção em um mercado de trabalho que exige, cada vez mais, mão-de-obra especializada e no qual importa quem tem poder aquisitivo para o consumo.

Para a realização da pauta de direitos, não basta apenas a sua proclamação. Assim, não é uma questão filosófica, moral ou jurídica, mas um problema cuja solução depende do desenvolvimento da sociedade. Diagnosticar as necessidades em cada microespaço político e territorial e desenvolver estratégias para minimizar esta questão constituem-se em um desafio a ser enfrentado pelo pacto entre Estado e sociedade civil.

No Brasil, apesar da existência do EDD, da democracia representativa e de uma Constituição cidadã, os resultados do estudo empírico revelaram um vínculo precário entre Estado e sociedade civil. Isto pode estar relacionado ao baixo grau de entendimento desta quanto aos seus Direitos Políticos. Em sua dimensão operacional, o PBF apresenta um caráter assistencialista, não emancipatório no que se refere à perspectiva do entendimento dos direitos e do exercício da cidadania ativa. 
Ainda com relação à avaliação do PBF, observou-se que este cumpre apenas um dos seus objetivos o de promover o alívio imediato da pobreza, por meio da transferência direta de renda à família. Parece não ter sido ainda atingido, pelo PBF, o objetivo de reforçar o exercício de direitos sociais básicos nas áreas de Saúde e Educação, por meio do cumprimento das condicionalidades, o que poderá contribuir para que as famílias consigam romper o ciclo vicioso da pobreza entre gerações. Do ponto de vista do alcance do objetivo administrativo de coordenação de programas complementares, isto se tem verificado na prática, embora não se traduza no desenvolvimento das famílias, de modo que os beneficiários do Programa Bolsa Família consigam superar a situação de pobreza na qual se encontram.

Conclui-se que, apesar de os dispositivos constitucionais da Carta Magna de 1988 assegurarem os Direitos Políticos e Sociais, isto não tem contribuído para ampliar o grau de entendimento dos beneficiários do Programa Bolsa Família sobre estes direitos. Eles apresentam baixo poder de pressão ante o Executivo e o Legislativo, têm baixa capacidade de participação e, conseqüentemente, menos oportunidade de encaminhar e obter atendimento nas suas demandas. O PBF, ao disponibilizar recursos para a alimentação e ao exigir a manutenção da criança na escola, poderá, no futuro, retirar da situação de pobreza em que se encontram os seus ascendentes.

Artigo recebido em 14.12.2007. Aprovado em 14.10.2008.

\section{NOTAS}

\footnotetext{
${ }^{1}$ Para efeito deste estudo considera-se população em situação de pobreza os beneficiários do Programa Bolsa Família. Por sua vez, para entrar no PBF, as famílias com renda mensal por pessoa de até $\mathrm{R} \$ 120,00$ devem procurar a Prefeitura de seu município e fazer o seu cadastro junto ao Cadastro Único dos Programas Sociais [CadÚnico]. A partir das informações do Cadastro Único, o Governo Federal seleciona as famílias com renda mensal de até R \$120,00 por pessoa. A seleção considera o orçamento disponível e as metas de expansão do Programa. Cada município tem um número estimado de famílias pobres considerado como a meta de atendimento do Programa naquele território específico. As famílias com renda mensal de até R\$ 60,00 por pessoa podem ser incluídas no Programa, independentemente de sua composição. Por sua vez, as famílias com renda mensal entre $\mathrm{R} \$ 60,00$ e $\mathrm{R} \$ 120,00$ por pessoa podem ingressar no Programa desde que tenham gestantes, nutrizes, crianças e adolescentes entre 015 anos.

${ }^{2}$ Os municípios pesquisados são: Salvador, Barreiras, Vitória da Conquista, Guanambi, Valença, Simões Filho, Catu, Santa Inês, Eunápolis e Senhor do Bonfim. Foram selecionados por possuírem Escolas Técnicas Federais, considerando-se que estes equipamentos públicos, por estarem próximos da comunidade local, podem contribuir para facilitar o acesso à educação técnica profissionalizante de nível médio e, conseqüentemente, ampliar a possibilidade da participação cidadã.

${ }^{3}$ Capital social é uma característica da organização, cuja moeda é a confiança, normas e sistemas que contribuem para aumentar a EFICIÊNCIA da sociedade, pois facilita a coordenação 'espontânea'. O capital social serve como uma espécie de garantia, estando disponível para os que não têm acesso aos mercados de créditos regulares. O que se empenha são as relações sociais. A constituição de crédito rotativo é mais do que uma simples instituição econômica; é um mecanismo que fortalece a solidariedade comunitária (Putnam, 1996).

${ }^{4}$ A quantidade de citações é superior à quantidade de observações, devido às respostas múltiplas (três no máximo).
}

\section{REFERENNCIAS BIBLIOGRÁFICAS}

Arretche, M. (2002). Federalismo e relações intergovernamentais no Brasil: a reforma de programas sociais. Revista de Ciências Sociais, 45(3), 431-458.

Bobbio, N. (2004). A era dos direitos. Rio de Janeiro: Campus.

Carvalho, A. I. (1995). Conselhos de saúde no Brasil. Rio de Janeiro: FASE/IBAM. 
Constituição da República Federativa do Brasil 1888. (1888). Texto consolidado. Recuperado em 9 setembro, 2006, de http://www.planalto.gov.br/ccivil_03/Constituicao/Constituiçao.htm

Constituição da República Federativa do Brasil 1988. Texto consolidado até a Emenda constitucional n. 52 de 6 de março de 200. Recuperado em 9 setembro, 2006, de http://www.planalto.gov.br/ccivil_03/Constituicao/Constituiçao.htm

Decreto n. 5.209, de 17 de setembro de 2004. (2004). Regulamenta a Lei no 10.836, de 9 de janeiro de 2004, que cria o programa bolsa família, e dá outras providências. Recuperado em 9 setembro, 2006, de http://www.planalto.gov.br/ccivil_03/_Ato2004-2006/2004/Decreto/D5209.htm

Di Pietro, M. S. Z. (2006). Direito administrativo. São Paulo: Atlas.

Dorella, P. J. (2006). Os direitos políticos nas Constituições Brasileira. Jus Navigandi, 19 (1). Recuperado em 16 outubro, 2006, de http://jus2.uol.com.br/doutrina/texto. asp?id=1502

Ferreira, P. (2002). Curso de direito constitucional (12a ed. ampliada e atual). São Paulo: Saraiva.

Hirschman, A. O. (1982). De consumidor a cidadão: atividades privadas e participação na vida pública (M. M. Levy, Trad.). São Paulo: Brasiliense.

Kliksberg, B. (2007). Cómo avanzar la participación en América Latina, el continente más desigual? Anotaciones estratégicas. Revista del CLAD. Reforma y Democracia, (37), 37- 80.

Lei n.10.836, de 9 de janeiro de 2004. (2004). Cria o programa bolsa família e dá outras providências. Recuperado em 9 setembro, 2006, de http://www.planalto.gov.br/ccivil_03/_Ato20042006/2004/Lei/L10.836.htm

Mashall, T. H. (1950). Citizenship and social class. London: Pluto Press.

Mendes, V. L. P. S., Marchi, C. M. D. F., Marchi, R. J. T., Barbosa, A. M. G., Oliveira, M C. V. P. da, Machado, K. M., Rodrigues, J. M. (2006). Modelos de gestão adotados pela administração pública na redução da pobreza das desigualdades sociais e participação cidadã. [Projeto]. Universidade Federal da Bahia, Salvador, BA., Brasil: Escola de Administração.

Mesquita, C. S. (2006). Contradições do processo de implementação de políticas públicas: uma análise do Programa Bolsa Família 2003-2006. Revista do Serviço Público. 57(4), 465-485.

Ministério da Saúde, \& Secretaria de Assistência à Saúde. (2002). Inovação gerencial em serviços públicos de saúde e cidadania (elaborado por V. L. P. S. Mendes) (Série B Textos Básicos de Saúde). Brasília: Ministério da Saúde.

Moraes, A. de (2005). Direito constitucional. São Paulo: Atlas.

Pinto, J. M. R. de, Brant, L. L. N. A. O. de, Sampaio, C. E. M., \& Pascom, A. R. P. (2000). Um olhar sobre os indicadores de analfabetismo no Brasil. Revista Brasileira de Estudos Pedagógicos, 81(199), 511-525.

Portaria n. 555, de 11 novembro de 2005. (2005). Estabelece normas e procedimentos para a gestão de benefícios do programa bolsa família, criado pela Lei 10.836, de 9 de janeiro de 2004. $\begin{array}{lllll}\text { Recuperado em } & 25 & \text { agosto, }\end{array}$ http://www.mds.gov.br/bolsafamilia/menu_superior/legislacao_e_instrucoes/portarias-1

Portaria $n^{o} .551$ de 9 novembro de 2005 (2005). Regulamenta a gestão das condicionalidades do Programa Bolsa-Família. Ministério do Desenvolvimento Social e Combate à Fome. $\begin{array}{lllll}\text { Recuperado em } & 25 & \text { agosto, } & 2006, & \text { de }\end{array}$ http://www.mds.gov.br/bolsafamilia/menu_superior/legislacao_e_instrucoes/portarias-1 
Putnam, R. D. (1996). Comunidade e democracia: a experiência da Itália moderna (L. A. Monjardim, Trad.). Rio de Janeiro: Fundação Getúlio Vargas.

Yin, R. K. (2005). Estudo de caso: planejamento e métodos (3a ed.). Porto Alegre: Bookman. 